\title{
OS GRUPOS DE APOIO COMO CANAL DE COMPARTILHAMENTO DA INFORMAÇÃO E DO CONHECIMENTO
}

\section{GRUPOS COMO EL CANAL DE APOYO COMPARTIDO DE INFORMACIÓN Y CONOCIMIENTO}

\author{
Armando Sergio de Aguiar Filho* \\ Monica Erichsen Nassif**
}

\begin{abstract}
RESUMO:
Introdução: O papel do compartilhamento da informação e do conhecimento que tende a provocar uma nova leitura dos canais de distribuição, possibilitando o amadurecimento do conceito de compartilhamento e sua relação com o processo de gestão da informação. Dessa interação surge variada gama de alternativas paras as organizações se relacionarem internamente com seus colaboradores e, externamente, com o seu público.

Objetivo: O objetivo é fazer um levantamento e apresentação dos estudos relativos aos canais de compartilhamento da informação e do conhecimento, procurando identificar seus correlatos na área da administração.

Metodologia: O trabalho foi desenvolvido a partir de uma pesquisa bibliográfica. Para tanto buscou-se num primeiro momento alinhar os conceitos e terminologias da área da ciência da informação e num segundo momento identificar uma abordagem diferenciada sobre o compartilhamento que contribuísse para validar a característica interdisciplinar da área informacional e a contribuição que outras áreas podem fazer para os estudos da gestão da informação e do conhecimento.

Resultados: A análise da pesquisa indicou considerações relevantes quanto ao entendimento das diversas abordagens utilizadas no que tange aos canais de compartilhamento, assim como as características comuns e diferenciadas destes meios e os impactos em suas dinâmicas.

Conclusões: A terminologia Grupo de Apoio é uma das diversas abordagens utilizadas no compartilhamento da informação e do conhecimento, e, tal qual as outras abordagens apresentadas permitem avaliar e promover serviços de informação mais adequados para atender as demandas específicas.
\end{abstract}

Palavras-chave: Conhecimento. Compartilhamento. Canais. Grupo de apoio.

*Doutor em Ciência da Informação pela UFMG. Docente da Faculdade de Ciências Econômicas, Administrativas e Contábeis. E-mail armandoaguiar@ig.com.br

**Doutora em Ciência da Informação. Professora Associada da Universidade Federal de Minas Gerais. E-mail mnassif@eci.ufmg.br 


\section{INTRODUÇÃO}

As transformações sociais e organizacionais da Era do Conhecimento têm exigido das empresas uma capacidade de aprendizagem cada vez maior. Associa-se a isto a crescente utilização e difusão da informação, que tem proporcionado mudanças importantes nos mais diversos setores da sociedade, tornando a gestão da informação um recurso fundamental para as organizações. Nesse sentido, a informação passa a ser tratada como recurso tão fundamental quanto o capital, a mão-de-obra e a tecnologia, sendo, portanto, considerada um ativo de grande relevância para agregar valor aos processos, produtos e serviços prestados pelas organizações. O conhecimento é o recurso econômico mais valioso para a competitividade das empresas e das nações e seu uso como fonte de vantagem competitiva sempre existiu. Assim, a aprendizagem, geração e compartilhamento do conhecimento não seria um novo pensamento revolucionário, mas sim, algo que as empresas sempre fizeram, porém, atualmente, com um nível maior de sofisticação.

De acordo com Nogueira (2003), a expressão "gestão do conhecimento" é utilizada há mais de duas décadas, no entanto é cada vez maior a necessidade de colocá-la em prática por duas razões: a primeira devido ao fato de que o capital intelectual passou a ser considerado um diferencial competitivo que pode colaborar para a sobrevivência no atual mercado econômico e a segunda, porque a necessidade de identificar, organizar, armazenar e proteger o conhecimento tornou-se imprescindível diante da acirrada concorrência estabelecida no ambiente empresarial.

Conforme Davenport e Prusak (1998), o benefício do conhecimento é proporcionar uma vantagem sustentável gerando retornos crescentes e continuados e, ao contrário dos ativos materiais, ele aumenta com o uso: ideias geram novas ideias e o conhecimento compartilhado permanece com o doador, ao mesmo tempo em que enriquece o recebedor.

Como a informação tem sido vista pelas instituições como um recurso capaz de agregar valor aos produtos e serviços por elas prestados, não basta às organizações possuírem informações de qualidade, é necessário disponibilizá-las adequadamente para o público certo, no tempo certo. Isso 
implica em saber como obter a informação, como organizá-la e como distribuíla, ou seja, implica em uma preocupação quanto ao gerenciamento da informação nas organizações. Drucker (1993), em sua análise de gestão da informação no ambiente empresarial evidencia que a organização tem que aprender a criar novos conhecimentos por meio da melhoria contínua de todas as suas atividades, mediante o desenvolvimento de novas aplicações com base em seus próprios sucessos e mantendo a inovação como processo organizado, visando responder ao desafio de aumentar continuamente a produtividade dos trabalhadores do conhecimento

Para Woodman (apud VIGNAU; MUNÕZ, 2012), para que haja adequado gerenciamento da informação é necessário saber coletar, processar e distribuir a informação. O autor chama a atenção, também, para a necessidade de as pessoas que lidam com a informação aplicarem suas habilidades e cooperarem entre si, fazendo com que o processo de gestão da informação possa contribuir efetivamente para 0 alcance dos objetivos organizacionais.

Para obterem sucesso em ambientes de constantes e profundas mudanças, as organizações precisam reexaminar suas estratégias e questionar seus processos informacionais. Os Administradores têm sido chamados a empreender esforços no sentido de compreender e interpretar a natureza dessas mudanças e de analisar as implicações para as suas empresas.

Vários estilos de gerenciamento de informação têm sido discutidos, mas ainda é grande o desafio de se utilizar adequadamente a informação. Muitas vezes administradores são levados a tomar decisões baseadas em sua intuição, uma vez que não dispõem ou não identificam informações adequadas para decidirem. De modo geral, as organizações possuem atualmente uma vasta gama de informações que poderiam se tornar conhecimento valioso, mas, dificilmente, as informações encontram-se disponíveis na forma apropriada ou no momento certo para utilização na solução de problemas. Iniciativas e projetos na área de informação vêm sendo realizados por meio da implantação de novas formas de gerenciamento da informação, do conhecimento e do capital intelectual. Governos têm utilizado a informação 
para desenvolver, aperfeiçoar e ampliar seus sistemas de informações com o objetivo de melhorar os serviços públicos prestados e de racionalizar seus processos de trabalho. De acordo com McGee e Prusak (1994), a informação, mais do que a terra ou o capital, é a força motriz na criação de riquezas e prosperidade na economia do conhecimento. Assim, as organizações precisam saber gerir e criar novos conhecimentos para sua competitividade no mercado atual, uma vez que ao dominarem este processo terão significativa vantagem sobre as demais.

Neste contexto, emerge o papel do compartilhamento da informação e do conhecimento que tende a provocar uma nova leitura dos canais de distribuição, possibilitando o amadurecimento do conceito de compartilhamento e sua relação com o processo de gestão da informação. Dessa interação surge variada gama de alternativas paras as organizações se relacionarem internamente com seus colaboradores e, externamente, com o seu público.

Segundo Choo (2003), em uma organização o conhecimento é amplamente disseminado e toma várias formas, mas sua qualidade é revelada na diversidade de capacitação que a organização desenvolve como resultado desse conhecimento. Para ele a eficácia do processo pode ser melhorada por meio de iniciativas de gerenciamento sistemático.

Uma das abordagens propostas para prática do compartilhamento da informação e do conhecimento é a do Grupo de Apoio que, para Tavares (2011), tem como principal objetivo contribuir para o processo de tomada de decisão, certificando-se de que as informações sejam oportunas, tenham relevância e propósito e mantenham-se com a qualidade e quantidade necessárias. Para o autor, a fim de atender as demandas do mercado e em função da competitividade e da produtividade observa-se a aproximação do modelo de oferta educacional ao funcionamento da economia com a aplicação de conceitos originários do meio econômico, como eficiência, produtividade, relações de mercado, clientelas e preferências dos consumidores ao meio educacional. A busca pela produtividade, eficiência e eficácia institucional levam as instituições à revisão dos modelos e metodologias com vistas ao 
planejamento e tomada de decisões, utilizando como principal recurso a informação e o conhecimento.

O objetivo deste artigo, realizado através de uma metodologia de revisão de literatura a partir de uma pesquisa bibliográfica, é fazer um levantamento e apresentação dos estudos relativos aos canais de compartilhamento da informação e do conhecimento, procurando identificar seus correlatos na área da administração, em especial a literatura de Grupos de Apoio, de forma a investigar onde e como as temáticas desta área se associam e se completam nas abordagens da ciência da informação e da gestão.

\section{CONHECIMENTO COMO VANTAGEM COMPETITIVA}

Para desenvolver uma análise do conhecimento como uma vantagem competitiva, diversos autores, a exemplo de Drucker (1993), destacam que o poder econômico das empresas está concentrado hoje no seu capital intelectual, definido como o único recurso significativo, atualmente, no gerenciamento da informação e do conhecimento e da geração de serviços, no lugar de ativos imobilizados.

De acordo com Davenport e Prusak (1998) a vantagem do conhecimento é uma vantagem sustentável. Para eles com o tempo, os concorrentes quase sempre conseguem se igualar, mas a empresa rica em conhecimento e gestora do conhecimento terá passado para um novo nível de qualidade, criatividade e eficiência. Ao contrário dos ativos materiais, que diminuem à medida que são usados, os ativos do conhecimento tendem a aumentar com a sua utilização. É importante destacar que o potencial de novas ideias surgidas do estoque do conhecimento de uma empresa é praticamente infinito, em especial se as pessoas da empresa têm a oportunidade de pensar, aprender e conversar umas com as outras. Choo (2003) contribui para a discussão do conhecimento como vantagem competitiva explicando que a simples existência de conhecimento em na organização é de pouca ajuda, uma vez que ele só é um ativo corporativo valioso quando está acessível e seu valor aumenta na proporção do grau de acessibilidade. O papel estratégico do conhecimento é 
também identificado por Nonaka (1999), para quem o conhecimento é valioso se for aplicável com êxito em atividades criadoras de valor/competências e for utilizável na exploração de oportunidades de negócios.

O compartilhamento do conhecimento amplia a capacidade de inovação e gera fontes de vantagem competitiva. Assim, Nonaka e Takeuchi (1997) concluem que o conhecimento torna-se um diferencial competitivo porque à medida que as companhias buscam novas formas de alavancar seus recursos para ganhar mais vantagens competitivas, a consciência de que o conhecimento que existe dentro de uma empresa é um de seus recursos mais importantes, aumenta.

A gestão da informação e do conhecimento é fundamental para as organizações se tornarem competitivas. A falta de uma estrutura organizacional sensível e atenta à gestão da informação impede a sinergia entre os diferentes setores, tanto em virtude do excesso como da falta de informação, ou mesmo o acesso de forma inadequada aos conteúdos informacionais pode levar os membros da organização a trabalhar com elevados níveis de tensão e imprecisão. Gerenciando a informação de forma integrada, a fim de usá-la no momento da tomada de decisão, as organizações desenvolvem processos e fluxos dinâmicos que possam buscar seu crescimento e evolução, contribuindo para a seleção e filtragem da informação que é mais adequada e relevante à tomada de decisão.

Davenport e Prusak (1998) descrevem que, ainda que os tomadores de decisão tenham acesso a uma grande quantidade de informações, a maioria presta atenção a determinados tipos, como por exemplo, financeiras, operacionais e mercadológicas; ou seja, a informação que de algum modo, esclareça melhor as incertezas estratégicas dos ambientes interno e externo à corporação. Isso não é uma regra: existem organizações que dão ênfase às informações dos clientes, dos concorrentes tradicionais e não-tradicionais, informações internas e, dependendo do ramo de atividade, definem sua estratégia de informação com informações de produtos gerados internamente, informações conseguidas junto aos fornecedores e parceiros, aperfeiçoamento da informação logística e informações dos próprios funcionários. 
Nas palavras de Carvalho (2001), gerenciar informação como um recurso organizacional, implica, primeiramente, em verificar as necessidades informacionais dos indivíduos da organização, na segunda etapa prospectar e coletar o que é relevante, em terceiro selecionar, organizar, tratar, armazenar, e por último disseminar, transferir e gerar novas necessidades. Torna-se assim necessário buscar metodologias e ferramentas para desenvolver essas atividades de maneira eficiente, a fim de gerar conhecimento que possa subsidiar o processo decisório.

\section{GESTÃO DA INFORMAÇÃO E DO CONHECIMENTO}

Para obterem sucesso em ambientes de constantes e profundas mudanças, as organizações precisam reexaminar suas estratégias e questionar seus processos informacionais. Os Administradores têm sido chamados a empreender esforços no sentido de compreender e interpretar a natureza dessas mudanças e de analisar as implicações para as suas empresas. Vários estilos de gerenciamento de informação têm sido discutidos, mas ainda é grande o desafio de se utilizar adequadamente a informação. Muitas vezes administradores são levados a tomar decisões baseadas em sua intuição, uma vez que não dispõem de informações adequadas. De modo geral, as organizações possuem atualmente uma vasta gama de informações que poderiam se tornar conhecimento valioso, mas, dificilmente, as informações encontram-se disponíveis na forma apropriada ou no momento certo para utilização na solução de problemas. Iniciativas e projetos na área de informação vêm sendo realizados por meio da implantação de novas formas de gerenciamento da informação, do conhecimento e do capital intelectual. Neste contexto, emerge o papel da Gestão da Informação e do Conhecimento, possibilitando o amadurecimento do conceito de compartilhamento e sua relação com o processo de gestão da informação. Dessa interação surge variada gama de alternativas paras as organizações se relacionarem internamente com seus colaboradores e, externamente, com o seu público. $O$ 
desafio é decodificar o modo de pensar, compreender e lidar com a realidade, oferecendo as informações necessárias para seu público relevante.

Barbosa, Sepúlveda e Costa (2009) definem Gestão do Conhecimento como um conjunto de processos por meio dos quais as organizações buscam, organizam, disponibilizam, compartilham e usam a informação e conhecimento com vistas à melhoria do seu desempenho. Para o autor estes processos são frequentemente facilitados pelo uso da tecnologia da informação e dependem do compartilhamento do conhecimento entre funcionários e da comunicação deste com outros setores.

Alvarenga Neto (2002) colabora definindo a Gestão do Conhecimento como um processo que incorpora várias abordagens gerenciais e ferramentas, capaz de ajudar no estabelecimento da gestão estratégica em relação a utilização da informação e do conhecimento no apoio da promoção da transferência de informações, da inovação, da aprendizagem, da criatividade e no fortalecimento das competências essenciais da organização. Importante destacar que estes autores expõem que administrar ou gerenciar o conhecimento não implica exercer controle direto sobre o conhecimento pessoal e na realidade o planejamento e gestão do contexto, das situações nas quais o conhecimento possa ser produzido, registrado, organizado, compartilhado, disseminado e utilizado de forma a possibilitar melhores decisões, melhor acompanhamento de eventos e tendências externas e uma contínua adaptação da empresa a condições sempre mutáveis e desafiadoras do ambiente onde a organização atua.

\section{CRIAÇÃO E COMPARTILHAMENTO DO CONHECIMENTO}

Para Nonaka e Takeuchi (1997), o desenvolvimento de uma organização está intimamente relacionado à sua capacidade de criar conhecimentos, disseminá-lo na organização e incorporá-lo a produtos, serviços e sistemas. Esse processo ocorre dentro de uma comunidade em interação que se expande, atravessando níveis e fronteiras interorganizacionais. O modelo dinâmico da criação do conhecimento está fundamento no pressuposto de que 
este é criado e expandido por meio da interação entre as dimensões tácito e o explícito, mediante quatro processos de conversão: socialização, externalização, combinação e internalização.

$\checkmark$ Socialização: converte o conhecimento Tácito em Tácito, por meio do compartilhamento de experiências, 0 aprendizado pela observação, imitação e prática.

$\checkmark$ Externalização: o conhecimento Tácito para o Explícito. È um processo de criação do conhecimento expresso nas metáforas, analogias, conceitos, hipóteses e modelos.

$\checkmark$ Combinação: conhecimento Explícito em Explícito. Processo de sistematização de conceitos em um sistema de conhecimento. As pessoas trocam conhecimentos através de documentos, reuniões, redes de computadores, conversas ao telefone.

$\checkmark$ Internalização: conhecimento Explícito para Tácito. Estar relacionado ao "aprender fazendo", sendo necessárias a verbalização e diagramação do conhecimento na forma de manuais ou histórias orais.

Desta forma a criação do conhecimento organizacional se dá pela interação contínua e dinâmica entre o conhecimento tácito e o explícito, que, por sua vez, é moldada pelas mudanças entre diferentes modos de conversão. Para Nonaka e Takeuchi (1997), esses quatro modos constituem o motor do processo de criação do conhecimento como um todo, sendo os mecanismos pelos quais o conhecimento individual é articulado e amplificado na organização.

Este processo ocorre em espiral, começando no nível individual e vai ascendendo, ampliando comunidades de interação que cruzam fronteiras entre seções, departamentos, divisões e organizações. A criação do conhecimento é um processo contínuo, direcionado pela intenção organizacional, que é definida como uma aspiração, de uma organização, às suas metas. A sua vantagem é a 
criação de um "ambiente de conhecimento", voltado para o compartilhamento, que gera mais competitividade e melhores decisões.

É difícil transferir ou disseminar grande volume de conhecimentos, sobretudo do tipo tácito, dentro da organização. Enquanto o conhecimento explícito é divulgado mediante ferramentas de rede ou de groupware, a transferência do tácito exige compartilhamento mediante socialização, proximidade física e bons relacionamentos, embora vários softwares de colaboração sejam extremamente úteis para apoiar o processo (NONAKA, 2001).O modelo de criação do conhecimento serve como um guia às organizações que desejam promover ou mesmo gerenciar o processo de criação do conhecimento mas algumas ressalvas devem ser feitas, em especial quanto a diferenças de vários fatores, como: pessoas, lugares, procedimentos e ambientes.

Segundo Davenport e Prusak (1998) há vários fatores que inibem a transferência do conhecimento: falta de confiança mútua, diferentes culturas, vocabulários e quadros de referência, falta de tempo e de locais de encontro; ideia estreita de trabalho produtivo, status e recompensas vão para os possuidores do conhecimento, falta de capacidade de absorção pelos recipientes, crença de que o conhecimento é prerrogativa de determinados grupos, síndrome do "não inventado aqui", intolerância com erros ou necessidade de ajuda.

\section{GRUPOS DE APOIO COMO ABORDAGEM FUNDAMENTAL PARA O COMPARTILHAMENTO}

O compartilhamento se dá por meio das interações dos indivíduos.

Muitas são as definições de grupos. Muitos também são os termos utilizados com os mesmos significados. Segundo Tjosvold (1993) grupos são duas ou mais pessoas que interagem e se influenciam diretamente, são mutuamente dependentes e têm papeis entrelaçados e normas comuns, e que se veem mutuamente como uma unidade na busca de objetivos comuns que satisfaçam suas necessidades e aspirações individuais. 
Os indivíduos estando ou não inseridos em grupos, tem insights e flashes, reorganizando uma determinada experiência, através de determinados estímulos do ambiente. Estes insights, derivados de um aprendizado cognitivo, se tornam úteis para as organizações a partir do momento que são interpretados e compartilhados pelo grupo, subsidiando a resolução de determinados problemas ou o desenvolvimento de determinados produtos e da inovação. Porém, as pessoas, ao fazerem parte de um determinado grupo, são responsáveis pelo seu crescimento e somente elas poderão ver sentido em suas ações perante o grupo. Deste modo, sua participação de maneira ativa ou passiva, colaborando ou não, no compartilhamento de experiências com este grupo, depende de suas escolhas e de seu estado interior.

Adler e Heckscher (2006) em estudos com grupos colaborativos que enfrentam desafios necessários para que possam melhorar o trabalho nas empresas onde estão empregados perceberam que estes desafios interligam e envolvem as pessoas. Os autores acreditam que devido ao motivo da atividade desses grupos ser de necessidade coletiva, porque sua realização irá fluir em benefício de todos, os impasses, que eles denominam de limites são mais fáceis de serem compreendidos do que os limites das comunidades tradicionais, nas quais os sujeitos têm uma pluralidade de necessidades e motivos.

Francis e Young (1992) apontaram benefícios no compartilhamento do trabalho em grupo, entre eles a participação e as relações positivas entre pessoas de diferentes credos, raças, idades, naturalidades, nacionalidades e classes sociais, o valor da cooperação e da tomada de decisão conjuntas construídas na participação democrática, a importância da iniciativa individual dentro do grupo, a liberdade de participar expressando pensamentos e sentimentos sobre assuntos que dizem respeito ao indivíduo do grupo ou do grupo como um todo, tendo o direito de se envolver no processo de tomada de decisões, empoderamento, que é valorizar o poder do grupo em ajudar seus membros a se sentirem bem, de tal forma que consigam usar suas habilidades e peculiaridades em favor de fazer a diferença em suas comunidades. Para estes autores quanto mais claros os participantes do grupo tiverem seus 
objetivos e valores em relação à sua participação no grupo, ou seja, em relação ao objeto que deva ser compartilhado, mais fácil será para atravessarem objetivos conflituosos e deixarem seus objetivos bem claros para o grupo. Os autores definem como importantes membros de um grupo aqueles que assumem os problemas que deverão enfrentar, bem como os desafios que aparecem, exploram, esclarecem e propõem objetivos, esclarecem critérios que objetivam sucesso nas ações do grupo, coletam e estruturam informações que sirvam como opções para ações, desenvolvem planos e estratégias e reveem o aprendizado e procuram melhorar a performance.

Vários autores da Ciência da Informação e da Administração defendem a ideia de um espaço de conhecimento compartilhado que encoraja e fomenta a participação em muitos níveis diferentes, promovendo a convivência.

Nonaka (1999) defende a ideia de um espaço de conhecimento compartilhado que encoraja e fomenta a participação em muitos níveis diferentes, promovendo a convivência. $O$ autor traz a definição de contexto capacitante, que é a criação de espaços para criação do conhecimento, promovendo interações entre os membros da organização por meio de forçastarefas, equipes e seminários. Os contextos capacitantes também surgem por geração espontânea. Aproxima-se deste conceito o de comunidade de prática, citado por Wenger (1998). Práticas de comunidade de prática implicam que os indivíduos aprendam com a participação nas práticas grupais. As fronteiras da comunidade de prática são definidas com nitidez pelas tarefas, cultura e história, já o contexto é caracterizado por seus participantes e pode ser mudado com facilidade. Na comunidade a composição é bastante estável e no contexto os membros entram e saem do grupo.

Para Lave e Wenger (1991) já que o conhecimento se torna uma fonte de vantagem competitiva, o processo de aprendizagem adquire especial relevância para a formulação de estratégias e para as demais ações que visam aumentar a competitividade da empresa. A criação de comunidades de prática visa proporcionar tais condições. Complementarmente, Lehesvirta (2004) considera que estas condições advêm de quatro subprocessos: intuir, interpretar, integrar e institucionalizar. A intuição ocorre a nível individual, 
quando determinados insights ou ideias vêm na mente de determinada pessoa. Estas ideias são interpretadas a um nível grupal, utilizando-se de determinada linguagem comum, significados compartilhados e compreensão. Quando o grupo passa a realizar uma determinada ação sobre o que foi interpretado, de uma maneira coletiva, há uma integração do aprendizado. Na fase final, que é a institucionalização, o que é aprendido por indivíduos e grupos, torna-se embutido nas estruturas e processos da organização e, portanto, começa a guiar o aprendizado novo, espontâneo e individual, e, o aprendizado no nível do grupo. Esta estruturação em diferentes níveis facilita a compreensão do papel das comunidades de prática no nível organizacional. Wenger e Snyder (2001) esclarecerem que, embora sejam auto organizadas e, portanto, resistentes à supervisão e à interferência, requerem esforços gerenciais para desenvolvê-las e integrá-las à organização. Para eles não existe um modelo de organização das comunidades de prática, algumas se reúnem no almoço, outras se comunicam por grupos de discussões, por reuniões semanais ou esporádicas, face a face ou através da Internet.

Nela os participantes compartilham compreensões sobre o que estão fazendo e o que isso significa em suas vidas e ambientes. O que impulsiona de fato as comunidades de prática são os objetivos comuns e a necessidade de aprender uns com os outros formando o saber coletivo. Para Fleury e Oliveira Junior (2001) os colaboradores necessitam trocar experiências com seus colegas e envolver esforços consideráveis para reunirem-se, partilharem histórias e construírem um conhecimento que os ajude a enfrentarem os problemas que surgem. Ser membro de uma comunidade de prática implica partilhar com os companheiros um processo contínuo de aprendizagem; implica não somente geração de conhecimentos, mas também de identidade.

O contexto de compartilhamento em práticas de grupo surge na abordagem de Davenport e Prusak (1998) através das redes informais. Para eles é possível que as melhores práticas do conhecimento fluam pelas redes informais que se desenvolvem nas organizações. Grande parte do trabalho nas empresas é feito porque as pessoas estão continuamente perguntando umas às outras através de redes informais quem sabe como fazer determinado 
trabalho. As redes informais têm vantagens e desvantagens, próprias da informalidade. Por funcionarem através de contatos informais e informação boca a boca, elas geram confiança que é a base essencial para o intercambio do conhecimento, além disso, são dinâmicas. A desvantagem é que por serem informais e não documentadas, não estão prontamente acessíveis a todos que precisam delas. Sua viabilidade depende de conversas casuais e contatos locais que por vezes funcionam bem, mas outras vezes, não.

$\mathrm{Na}$ administração a abordagem de contextos capacitantes, comunidades de práticas e redes informais é apresentada por Tavares (2011) com a nomenclatura de Grupos de apoio. Para ele o processo de gestão estratégica nas organizações necessita de um arranjo que busque a governabilidade da organização face ao que se pretende dela. Este processo deve abranger as dimensões pessoais, funcionais e de recursos que permeiam todas as áreas da organização. A formalização de um grupo de apoio deve estar subordinada a determinadas condições: o grupo deve ser constituído por pessoas que estejam diretamente envolvidas e comprometidas, de algum modo, com o presente e com o futuro da organização. Entre algumas de suas condições essenciais, os participantes devem ter uma visão conceitual da organização e do setor, ter uma visão crítica da organização, ter credibilidade junto aos colegas e subordinados, representarem todas as áreas envolvidas no processo e serem capazes de cumprir os compromissos assumidos. As pessoas que fazem parte da composição deste grupo possuem algumas responsabilidades como difundir o processo, compartilhar e disseminar o conhecimento, obter participação e envolvimento de seus colegas, indicar pessoas para participar em momentos específicos do processo, identificar problemas e disfunções e contribuir para que os mesmos sejam eliminados, minimizados ou mantidos sobre controle. A tarefa do grupo é catalisar o processo, certificando-se de que as informações sejam oportunas, tenham relevância e propósito e mantenham a qualidade e quantidade necessárias para orientar a tomada de decisão. $O$ grupo também busca a criação de um clima favorável e a busca sistemática do comportamento proativo da organização. $\mathrm{O}$ autor destaca que nos grupos de apoio é necessário diferenciar participação de engajamento. São ações 
diferentes. Estar engajado significa não só participar, como também sentir-se plenamente responsável por fazer com que um objetivo se realize. Participar não requer, em si, comprometimento ou engajamento.

Concomitantemente aos conceitos de participação e engajamento, fazse necessário analisar a perspectiva de envolvimento e comprometimento das pessoas que fazem parte do grupo de apoio. O envolvimento representa a identificação das pessoas com a proposta, enquanto o comprometimento refere-se ao estabelecimento e cumprimento de compromissos em relação ao que se propõe a realizar. A percepção do grupo é em grande parte um somatório das percepções de cada um dos envolvidos no processo. À medida que cada um explicita seu grau de comprometimento fica mais fácil avaliar as perspectivas de sucesso do processo de compartilhamento.

Uma vez agrupados e engajados, os membros do grupo de apoio devem estar capacitados para o desenvolvimento das seguintes atividades:

$\checkmark$ Monitoramento do ambiente externo, tanto no nível macro como junto aos relacionamentos externos e ambiente competitivo da organização.

$\checkmark$ Monitoramento interno, compreendendo a constante adequação da organização para responder aos desafios e demandas do ambiente externo.

$\checkmark$ Recomendação da necessidade de elaboração e coordenação da execução de planos específicos.

$\checkmark$ Implementação de mudanças sugeridas nesses cursos de ação.

$\checkmark$ Acompanhamento e avaliação das atividades desenvolvidas para o cumprimento das decisões tomadas no âmbito do grupo.

Os autores, tanto da Administração quanto das Ciências da Informação sustentam que ainda não existe uma fórmula aplicável a todas as organizações, uma vez que cada organização é única. Comungam do fato de que o fator crítico para a condução de processos de compartilhamento é a compreensão das características e possibilidades das pessoas e recursos 
Armando Sergio de Aguiar Filho. Monica Erichsen Nassif.

Os grupos de apoio como canal de compartilhamento da informação e do conhecimento

envolvidos e que práticas bem sucedidas de compartilhamento sinalizam para as seguintes premissas:

$\checkmark$ Comprometimento da alta direção

$\checkmark$ Assentamento em um significado e direção baseados na visão e missão da organização

$\checkmark$ Fortalecimento e motivação dos colaboradores

$\checkmark$ Adoção da comunicação efetiva utilizando redes formais e informais

$\checkmark$ Não-satisfação com obtenção apenas de resultados parciais

$\checkmark$ Institucionalização do processo

\section{CONSIDERAÇÕES FINAIS}

Os diversos estudos de canais de compartilhamento da informação e do conhecimento tentam abarcar a realidade no período temporal que se pretende investigar. Ainda assim, as possibilidades de interpretações são inúmeras. As tecnologias, as necessidades, a cultura de uma determinada época e local, estudados irão indubitavelmente variar de um pesquisador para outro e caberá à Ciência da Informação o papel de incorporar essa multiplicidade que o tema oferece. Os autores, tais Tavares (2011), Davenport e Prusak (1998), Nonaka (1999) e Barbosa (2008) sustentam que ainda não existe uma fórmula aplicável a todas as organizações, uma vez que cada organização é única. Comungam do fato de que o fator crítico para a condução de processos de compartilhamento é a compreensão das características e possibilidades das pessoas e recursos envolvidos. O Grupo de Apoio se posiciona, assim, como uma das inúmeras possibilidades de estudar os contextos destes processos, bem como seus usuários, dinâmicas e resultados e, ainda assim, o assunto não se esgotará, uma vez que se trata de um campo com vasto potencial exploratório. É importante destacar que o uso da informação passa obrigatoriamente por considerar as especificidades de cada contexto/meio no qual o usuário se encontra. 
Este artigo traz uma contribuição importante aos estudos da gestão da informação e do conhecimento, pois tem como propósito possibilitar uma reflexão sobre as diversas abordagens de canais de compartilhamento e atinge seu objetivo uma vez que apresenta uma nova abordagem - grupo de Apoio para sistemas de compartilhamento de informação e conhecimento já amplamente analisados na literatura informacional, como contextos capacitantes, comunidades de práticas e redes formais e informais.

Para trabalhos futuros recomenda-se a análise de um caso real de um Grupo de Apoio, de forma a identificar seus processos, usuários, ferramentas e resultados que possam dar respostas sobre até que ponto este grupo de compartilhamento da informação e do conhecimento é um meio eficiente para a ação, discussão e integração de pessoas em um determinado grupo.

\section{REFERÊNCIAS}

ADLER, P. S.; HECKSCHER, C.. Towards collaborative community. In: ADLER, P. S., HECKSCHER, C. The firm as a collaborative community: reconstructing trust in the knowledge economy. Oxford: Oxford University Press, 2006. p. 11-105.

ALVARENGA NETO. R. C. D. Gestão da Informação e do Conhecimento nas Organizações. 2002. Dissertação (Mestrado em Ciência da informação) Escola da Ciência da Informação, Universidade Federal de Minas Gerais, Belo Horizonte, 2002.

BARBOSA, R. R.. Gestão da informação e do conhecimento: origens, polêmicas e perspectivas. Informação \& Informação, Londrina, v. 13, n. 1, p. $1-25,2008$.

BARBOSA, R. R.; SEPÚLVEDA, M. I. M.; COSTA, M. U. P. Gestão da informação e do conhecimento na era do compartilhamento e da colaboração. Informação \& Sociedade, João Pessoa, v. 19, n. 2, p. 13-24, maio/ago. 2009.

CARVALHO, E. L. Informação orgânica: recurso estratégico para tomada de decisão pelos membros do Conselho de Administração da Universidade Estadual de Londrina. 2001. 93f. Dissertação (Mestrado em Ciência da Informação) - Faculdade de Biblioteconomia e Ciência da Informação, Pontifícia Universidade Católica de Campinas, São Paulo, 2001. 
CHOO, C. W. A organização do conhecimento: como as organizações usam a informação para criar significado, construir conhecimento e tomar decisões. 3. ed. São Paulo: Senac, 2003.

DAVENPORT, T. H.; PRUSAK, L. Conhecimento empresarial: como as organizações gerenciam seu capital intelectual. 3. ed. Rio de Janeiro: Campus, 1998.

DRUCKER, P. F. Sociedade pós-capitalista. São Paulo: Pioneira, 1993.

FLEURY, M. T. L.; OLIVEIRA JUNIOR, M. M. (Org.). Gestão estratégica do conhecimento: integrando aprendizagem, conhecimento e competências. São Paulo: Atlas, 2001.

FRANCIS, D.; YOUNG, D. Improving work groups: a practical manual for team building. San Diego: Pfeiffer e Company, 1992.

LAVE, J.; WENGER, E. C. Situated learning: legitimate peripheral participation. Cambridge: Cambridge University Press, 1991.

LEEHESVIRTA, T. Learning processes in a work organization: from individual to collective and/orvice versa? Journal of Workplace Learning, v. 16, p. 92100, 2004.

McGEE, J. V.; PRUSAK, L. Gerenciamento estratégico da informação. 2. ed. Rio de Janeiro: Campus, 1994.

NOGUEIRA, V. C. Gestão do Conhecimento: um estudo exploratório sobre as consequências provocadas pela perda de competências individuais segundo a percepção dos funcionários de TI. 2003. 128f. Dissertação (Mestrado em Engenharia de Produção) - Universidade Federal de Santa Catarina UFSC, Florianópolis, 2003.

NONAKA, I.. A dynamic theory of organizational knowledge creation.

Organization Science, Linthicum, v. 5, n. 1, p. 14-37, 1999.

NONAKA, I. The Knowledge-creating company. Harvard Business Review, New York, v. 69, n. 6, p. 96-104, Nov./Dec. 2001.

NONAKA, I.; TAKEUCHI, H.. Criação do conhecimento na empresa. Rio de Janeiro: Campus, 1997.

TAVARES, M. C. Gestão Estratégica. 3. ed. São Paulo: Atlas, 2011.

TJOSVOLD, D. Learning to manage conflict: getting people to work together. New York. Lexington Books, 1993. 
VIGNAU, B. S. S.; MUÑOZ, J. V. R. La información como recurso en el desarrollo de las organizaciones de las administraciones públicas. Anales de Documentación, Múrcia. n.3. p. 155-165, 2000. Disponível em: <http://revistas.um.es/analesdoc/article/view/2441>. Acesso em: 22 de dezembro de 2012.

WENGER E. C. Communities of practice: learning, meaning and identity. Cambridge: Cambridge University Press, 1998.

WENGER E. C.; SNYDER, W. M. Comunidades de prática: a fronteira organizacional. In: HARVARD BUSINESS REVIEW (Org.). Aprendizagem organizacional. Rio de Janeiro, 2001. p. 9-26.

\title{
Title
}

Groups like the Support Sharing Channel of Information and Knowledge

\begin{abstract}
Introduction: The role of sharing information and knowledge which tends to lead to a new understanding of distribution channels, allowing the maturation of sharing concept and its relationship to the process of information management. This interaction arises range of alternatives par as organizations relate internally with employees and externally with your audience.

Objects: The goal is to survey and presentation of studies related to information sharing and knowledge channels, trying to identify its correlates in the area of administration.

Methodology: The work was developed from a literature search. For both sought to initially align the concepts and terminology of information science area and a second time to identify a differentiated approach to sharing that would contribute to validate the interdisciplinary character of the information area and the contribution that other areas can make to the studies of information management and knowledge.

Results: The analysis of the survey indicated considerations relevant to the understanding of the various approaches used in relation to the sharing of channels, as well as the common and different characteristics of these media and the impact on their dynamics.

Conclusions: The Support Group terminology is one of several approaches used in the sharing of information and knowledge, and, like the other approaches presented to assess and promote better information services to meet the specific demands.
\end{abstract}

Keywords: Knowledge. Sharing. Channels. Support group.

\section{Titulo}

Grupos como el canal de apoyo compartido de información y conocimiento

\section{Resumen}


Introducción: La función de compartir la información y el conocimiento que tiende a conducir a una nueva comprensión de los canales de distribución, lo que permite la maduración de intercambio concepto y su relación con el proceso de gestión de la información. Esta interacción surge gama de alternativas organizaciones párrafos se relacionan internamente con los empleados y externamente con su público.

Objetivo: El objetivo es estudiar y presentación de los estudios relacionados con los canales de conocimiento y el intercambio de información, tratando de identificar sus correlatos en el área de administración.

Metodología: El trabajo se desarrolló a partir de una búsqueda en la literatura. Por tanto buscó alinear inicialmente los conceptos y la terminología del área de ciencias de la información y una segunda vez para identificar un enfoque diferenciado para compartir que contribuiría a validar el carácter interdisciplinario de la zona de información y la contribución que otras áreas pueden aportar a la Los estudios de gestión de la información y el conocimiento.

Resultados: El análisis de la encuesta indicó consideraciones relacionadas con la comprensión de los diversos enfoques utilizados en relación con la distribución de los canales, así como las características comunes y diferentes de estos medios y el impacto en su dinámica.

Conclusiones: La terminología grupo de apoyo es uno de los varios enfoques utilizados en el intercambio de información y conocimiento, y, al igual que los otros enfoques presentados para evaluar y promover mejores servicios de información para satisfacer las demandas específicas.

Palabras clave: Conocimiento. Intercambio de canales. Grupo de apoyo.

Recebido em: 10.04.2016

Aceito em: 18.11.2016 